\title{
Internal forces analysis of gas permeable shelter with emphasis on short-delay blasting
}

\author{
Aleksandr Leshchinskiy ${ }^{1}$, Evgeniy Shevkun ${ }^{1}$, Aleksandr Lovtsov $^{2}$ and Olga Kostiunina ${ }^{2 *}$ \\ ${ }^{1}$ Pacific National University, Transport and Power Engineering Faculty, Khabarovsk, Russia \\ ${ }^{2}$ Pacific National University, Engineering Faculty, Khabarovsk, Russia
}

\begin{abstract}
A mathematical model of transformable gas permeable blasting shelter made from worn out tires of heavy trucks bound together with chains, ropes or cables is proposed. Large displacements and unilateral constraints are specific features of this model. An algorithm was developed to calculate the displacements of tires and internal forces in connecting elements of blasting shelter subjected to dynamic loading. The results of the numerical simulation of simple shelter are presented for assessment of the adequacy of the mathematical model. This algorithm can be used to determine the parameters of shelter such as mass, number of tires, diameter of connecting elements which ensure its safe operation under any sequence of explosions.
\end{abstract}

\section{Introduction}

Blasting is a fast and efficient way of rock fragmentation. It is commonly used not only in the mining industry but also in civil engineering, construction and reconstruction of roads and railway lines. Position of the Far East region provides favorable conditions for domestic and international transportation. There is a direct railway access to several major border-crossing terminals. At the same time the density of railway network remains quite low in the regions of Siberia and the Far East. It curbs economic and industry growth in certain regions [1]. Prospects for the development of transport and communication conditions in the Far East are considered by Antonov [2].

Rock fragmentation by blasting is accompanied by flyrock which is a potential source of numerous hazards to people, surrounding objects and environment. Flyrock accidents in surface mining are analysed by Kecojevic and Radomsky [3]. A new mass explosions technology for destruction of semi-rocky and rocky soils preventing flyrock was developed at Pacific National University [4, 5, 6]. It is based on the use of blast holes with air-deck in overdrill along with transformable gas permeable blasting shelter made from worn out tires of heavy trucks bound together with chains, ropes or cables. Experiments carried out on the sites of federal highway \#58 "Amur" proved predictability, effectiveness and estimated safety of the developed technology. An example of blasting shelter for a mass explosion conducted on 12.04.07 is shown in Figure 1, a. Explosions were made row by row (rows 1-

* Corresponding author: 006934@pnu.edu.ru 
3) with 0.02 seconds (s) delay (Fig. 1, b). Two additional rows 4 and 5 were added to ensure safety on the village side.

a)

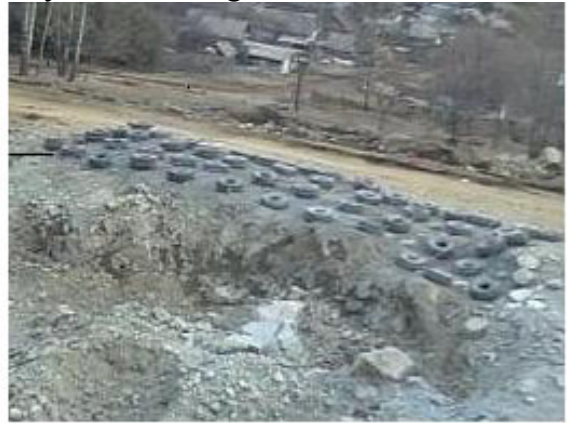

b)

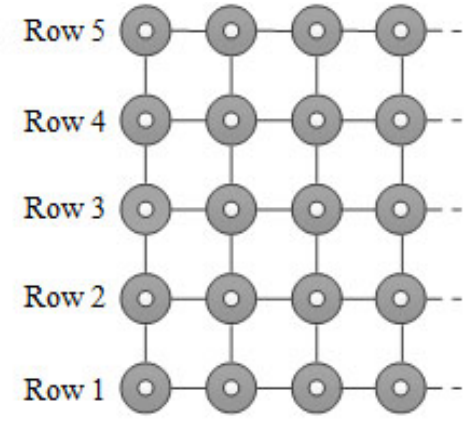

Fig. 1. (a) View of blasting shelter for mass explosion on 12.04.07; (b) Fragment of the model

Currently, mining industry tends to point blasting instead of multiple row blasting. It was caused by two factors: technological development in blasting (shift from detonating chord to non-electric detonation system etc.) and new requirements implemented to reduce seismic impact on nearby settlements. The environment friendly method of rock fragmentation by blasting is proposed in the latest researches. It combines the use of blast holes of special design $[4,7]$ with gas permeable blasting shelter [8] and point blasting with long-period delays [9-13]. However, the existing computational techniques do not allow to estimate the behavior of the shelter under various sequences of explosions.

An algorithm was developed for the analysis of the transformable gas permeable blasting shelter [14]. Numerical experiments showed that maximum flight height of the tires depends on delay intervals and detonation sequence of the blast holes. Employed mathematical model was verified by full-scale experiment carried out on 12.04.07 on the site of federal highway \#58 "Amur" near Teploozersk village (Fig. 1, a). In present research the mathematical model is modified by adding frictional forces acting on the tires which are in contact with the earth's surface.

\section{Model and methods}

The dynamic spatial model of blasting shelter is represented by concentrated masses connected using elastic weightless incompressible elements. The problem solving involves the combination of two types of nonlinearity: geometrical nonlinearity associated with large displacements and unilateral contact which emanates from the fact that contact region changes due to deformation of the elements. Contact region is defined by a set of "switched on" elements: elastic elements under tensile stresses and supports with compressive interaction forces between surface and tires (Fig. 2).
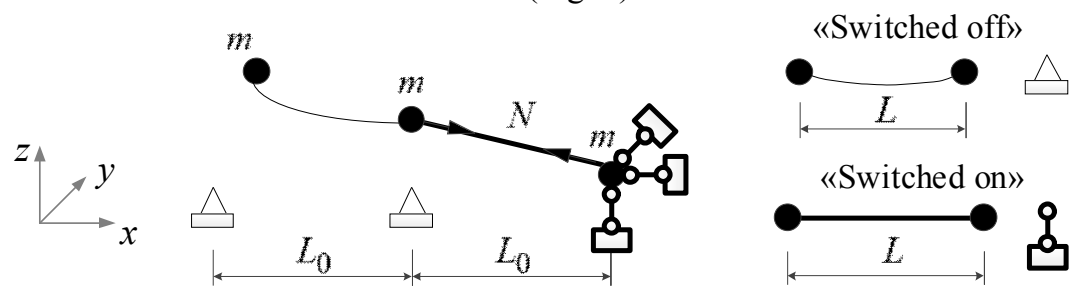

Fig. 2. "Switched on" elements and supports

Time discretization techniques are used for dynamic contact problems and the corresponding contact problem is solved at each time step using the appropriate numerical 
method [15-17]. There are many papers on nonlinear dynamics of geometrically nonlinear systems. The conceptual bases are given by Crisfield and Oller [18-20].

The shelter is exposed to short-term loads which are idealized by instantaneous impulses. Thus, the problem leads to investigating the behavior of the system under the action of its own weight and instantaneous impulses, applied at different times to different masses. We denote this load as $\mathbf{F}(t, x, y)$. Equation of motion can be written as

$$
\begin{aligned}
& \mathbf{M} \ddot{\mathbf{z}}(t)+\mathbf{R}(t) \mathbf{z}(t)=\mathbf{F}(t, x, y), \\
& \mathbf{z}(0)=0, \\
& \dot{\mathbf{z}}(0)=\dot{\mathbf{z}}_{0},
\end{aligned}
$$

where $\mathbf{z}(t), \dot{\mathbf{z}}(t), \quad \ddot{\mathbf{z}}(t)$ are nodal displacements, velocities and accelerations, $\mathbf{M}-$ diagonal mass matrix, $\mathbf{R}(t)-$ dynamic stiffness matrix at the moment $t$.

Only nonnegative vertical displacements are considered due to unilateral contact between surface and tires

$$
\begin{gathered}
\mathbf{w}(t) \geq 0 \\
\mathbf{z}(t)=\left\{\begin{array}{c}
\mathbf{u}(t) \\
\mathbf{v}(t) \\
\mathbf{w}(t)
\end{array}\right\},
\end{gathered}
$$

where $\mathbf{u}(t), \mathbf{v}(t)$ are horizontal displacements of masses, $\mathbf{w}(t)$ - vertical displacements of masses (Fig. 3, a).

a)

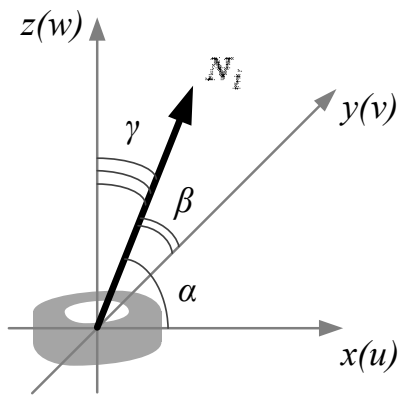

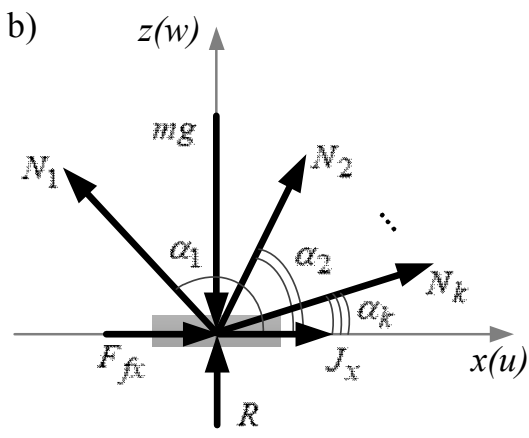

Fig. 3. (a) Displacements and internal forces in Cartesian coordinate system; (b) The forces acting on a tire in contact with surface

The equilibrium equations for a single tire at the moment when it is in contact with surface (Fig. 3, b):

$$
\begin{aligned}
& \sum F_{x}=0: J_{x}+N_{1} \cos \alpha_{1}+N_{2} \cdot \cos \alpha_{2}+\ldots+N_{k} \cdot \cos \alpha_{k}+F_{f x}=0 ; \\
& \sum F_{y}=0: J_{y}+N_{1} \cos \beta_{1}+N_{2} \cdot \cos \beta_{2}+\ldots+N_{k} \cdot \cos \beta_{k}+F_{f y}=0 ; \\
& \sum F_{z}=0: N_{1} \cdot \cos \gamma_{1}+N_{2} \cdot \cos \gamma_{2}+\ldots+N_{k} \cdot \cos \gamma_{k}-m g+R=0 ;
\end{aligned}
$$

where $N_{i}$ - internal force in the elastic element, $J_{x}, J_{y}$-inertia forces, $R$-constraint reaction force perpendicular to the surface, $F_{f x}, F_{f y}$ - the $x$ and $y$ components of actual friction force. 
If the tire is in contact with surface the actual friction force $F_{f}$ does not exceed the force of kinetic friction:

$$
\begin{gathered}
F_{f} \leq \mu \cdot R, \\
F_{f}=\sqrt{F_{f x}^{2}+F_{f y}^{2}},
\end{gathered}
$$

where $\mu$ is the coefficient of friction.

When the tire is detached from the surface: $w(t)>0$ and $F_{f}=0$. If $F_{f}<\mu \cdot R$ there is no horizontal movement of the tire and constraints are imposed to it in $x y$ plane. Otherwise $F_{f}=\mu \cdot R$ and sliding occurs between the tire and surface.

When the system experiences deformation a set of "switched off" elastic elements is defined by current length of each element $L$ (Fig. 2). If current length of the element due to deformation is less than initial length $L_{0}$, then this element is not taken into consideration because it doesn't affect stiffness of the system:

$$
L<L_{0}
$$

Various time integration strategies can be used to solve equation (1) with the Newmark methods being very popular. Dynamic equilibrium is considered at the end of the time step:

$$
\mathbf{M} \ddot{\mathbf{z}}_{n+1}+\mathbf{R}_{n+1} \mathbf{z}_{n+1}=\mathbf{F}_{n+1} \text {. }
$$

The solution of this equation can be obtained using a "predictor-corrector technique" [19]. Equation (5) provide an incremental "predictor step" $\Delta \mathbf{z}$ :

$$
\Delta \overline{\mathbf{F}}=\overline{\mathbf{R}}_{n} \Delta \mathbf{z}
$$

where $\Delta \overline{\mathbf{F}}=\left(\mathbf{F}_{n+1}-\mathbf{F}_{n}\right)+\mathbf{M}\left(\frac{4}{\Delta t} \dot{\mathbf{z}}_{n}+2 \ddot{\mathbf{z}}_{n}\right), \quad \overline{\mathbf{R}}_{n}=\mathbf{R}_{n}+\frac{4}{\Delta t^{2}} \mathbf{M}, \quad \mathbf{R}_{n}-$ static tangent stiffness matrix.

Having solved (5) for $\Delta \mathbf{z}$, the incremental displacements, velocities and accelerations at step $n+1$ are obtained. Then Newton-Raphson corrector is employed.

Nodal coordinates of the masses change as the system experiences deformation and current length of the elastic elements is calculated at each time step. Inequalities (2) - (4) are analyzed to define contact region when Newton-Raphson at step $n+1$ converges. If contact region at step $n+1$ differs from step $n$ "predictor-corrector step" should be repeated. Otherwise we move to the next step.

\section{Numerical simulation}

Simple model of blasting shelter (Fig. 4) was taken for numerical simulation. The shelter consists of 5 tires weighing $280 \mathrm{~kg}$ each bound together with $6.2 \mathrm{~mm}$ cables. A single blast hole is located under the central tire $m_{C}$.

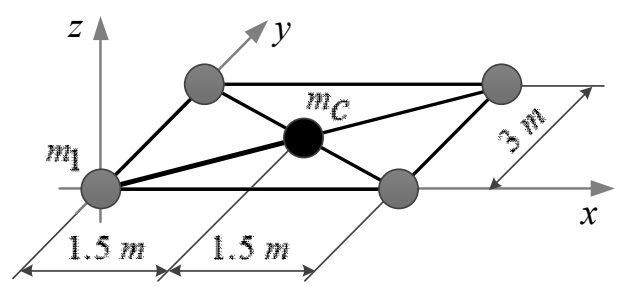

Fig. 4. Blasting shelter 
Initial velocity $V_{0}$ of the central tire after explosive detonation set to $6 \mathrm{~m} / \mathrm{s}$. If the tire is not a part of the shelter its flight height equals $h_{\max }=V_{0}^{2} / 2 g=1.83 \mathrm{~m}$. The coefficient of friction for rocky soil $\mu=0.3-0.5$. Considering the most unfavorable conditions $\mu$ equals 0.5 . Time integration step set to $2 \cdot 10^{-4} \mathrm{~s}$.

According to the simulation results the maximum flight height of the shelter is $0.708 \mathrm{~m}$. It takes $0.25 \mathrm{~s}$ for the central tire to reach this altitude (Fig. 5, a). The maximum internal force in the diagonal elastic element is $17.7 \mathrm{kN}$ (Fig. 5, $d$ ).

The numerical results depend on the time step $\Delta t$. The values of maximum vertical displacement of the central tire and the maximum internal force in the diagonal elastic element depending on integration step size are shown in Table 1. The analysis shows that the displacement converges with a decrease in the integration step size and tensile force requires more detailed consideration. The values of internal force in the diagonal elastic element for $t=0.16 \mathrm{~s}$ are also presented in Table 1 . The percent error is defined by the expression $\delta=\frac{N(j)-N(r)}{N(r)} \cdot 100$, where $j \in 1 \ldots r, N(j)$ - internal force corresponding to integration step size in the row $j$ of Table 1, $N(r)$ - tensile force corresponding to the minimum value of integration step size in the range of values considered in this study. In accordance with the calculation results the convergence of the tensile force can be observed in a certain range of values $\Delta t$. Further decrease of the integration step size leads to increase in the percent error.

Table 1. The dependence of numerical results on integration step size

\begin{tabular}{|c|c|c|c|c|c|}
\hline $\mathrm{j}$ & $\begin{array}{c}\text { Integration } \\
\text { step size } \\
\Delta t \cdot 10^{-4}, \mathrm{~s}\end{array}$ & $\begin{array}{c}\text { Maximum vertical } \\
\text { displacement of the } \\
\text { central tire, } \mathrm{m}\end{array}$ & $\begin{array}{c}\text { Maximum internal } \\
\text { force in the diagonal } \\
\text { elastic element, } \mathrm{kN}\end{array}$ & $\begin{array}{c}\text { Internal force in } \\
\text { the diagonal } \\
\text { elastic element } \\
\text { for } \mathrm{t}=0.16 \mathrm{~s}, \mathrm{kN}\end{array}$ & $\delta, \%$ \\
\hline 1 & 5 & 0.705 & 17.668 & 9.265 & 24 \\
\hline 2 & 2.5 & $0 / 707$ & 17.687 & 8.284 & 11 \\
\hline 3 & 2 & 0.708 & 17.704 & 7.461 & 0.1 \\
\hline 4 & 1 & 0.708 & 17.704 & 7.456 & 0.06 \\
\hline 5 & 0.625 & 0.708 & 17.701 & 7.521 & 0.9 \\
\hline 6 & 0.5 & - & - & 7.452 & - \\
\hline
\end{tabular}

The analysis of movement of the tires shows that the central tire pulls the corner tires of the blasting shelter when it goes up and the friction forces between the corner tires and the surface arise as a result. In figure 6 the functions of the actual friction force $F_{f}(t)$ and the force of kinetic friction $\mu \cdot R(t)$ acting on a corner tire are drawn. When these two lines are coincident the corner tires slide on a surface.

The system is symmetric so the absolute values of corner tires displacements are equal. The corner tire detaches from the surface for the first time at $t=0.08 \mathrm{~s}$. It hit the surface at $t=0.13 \mathrm{~s}$ and internal force in the diagonal elastic element at this moment is zero (the element is "switched off"). The corner tire rests on a surface until diagonal element "switches on" (Fig. 5, b,c). The central tire continues to move upward and it leads to a sudden change of contact region at $t=0.15 \mathrm{~s}$. Elastic elements located along the perimeter are "switched off" throughout observation period. 
a)

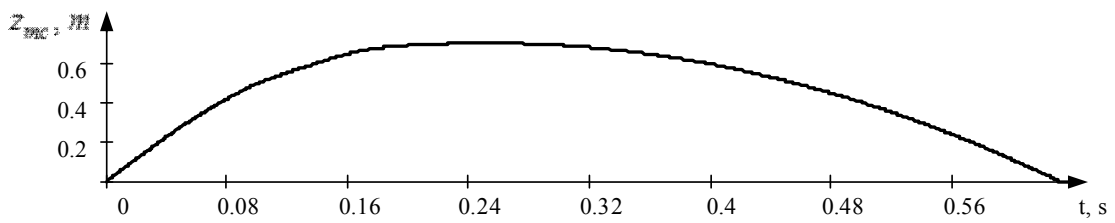

b)

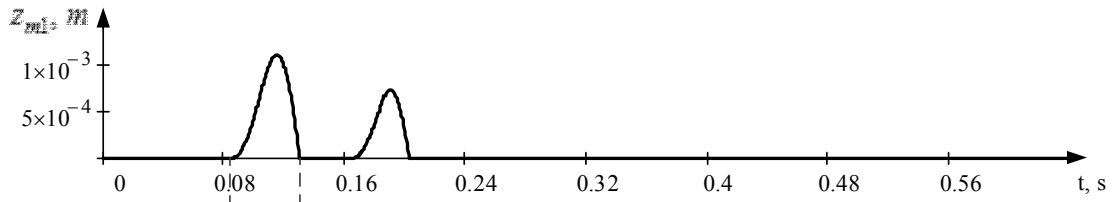

c)

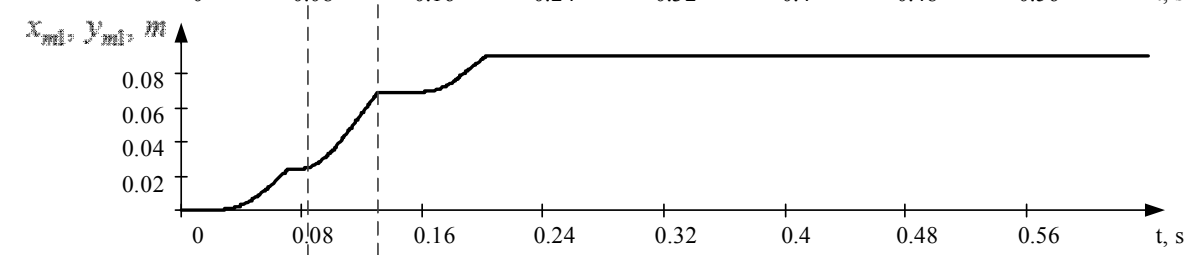

d)

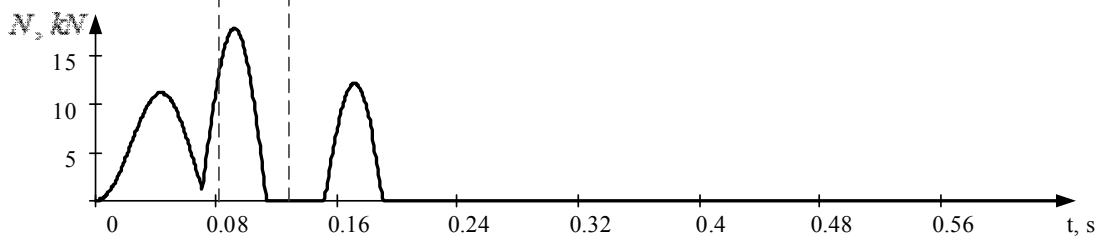

Fig. 5. (a) Vertical displacements of the central tire, (b) Vertical displacements of the corner tire, (c) Horizontal displacements of the corner tire, (d) Internal force in the diagonal elastic element as function of time

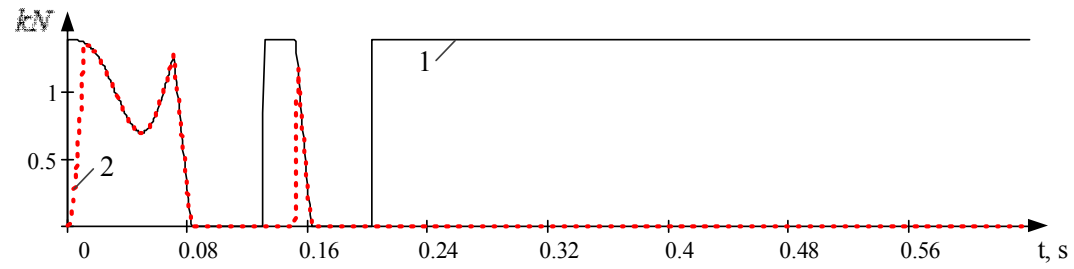

Fig. 6. 1 - Function of the force of kinetic friction $\mu \cdot R(t) ; 2$ - Function of the actual friction force $F_{f}(t)$

\section{Conclusion}

The dynamic spatial model of gas permeable blasting shelter is represented by concentrated masses interacting with unilateral foundation and by elastic weightless incompressible elements. The contact of mass with a surface in vertical direction is represented by nonpenetration condition and in the horizontal directions is governed by Coulomb friction. Time discretization technique is used to obtain numerical solution of the problem. Contact region is defined at each time step.

The algorithm was developed for nonlinear dynamic analysis of transformable gas permeable blasting shelter. The behavior of blasting shelter under various sequences of explosions can be investigated using proposed algorithm. The results of numerical simulation of simple shelter are presented for assessment of the adequacy of the mathematical model. 


\section{References}

1. Strategiya razvitiya zh. - d. transporta RF do 2030 goda. Utv. rasporyazheniem Pravitelstva RF ot 17 june 2008 g. \# 877-r.

2. S. L. Antonov, Proektirovanie razvitiya regionalnoy seti zh.-d., 4, 8. (2016).

3. V. Kecojevic, M. Radomsky, Safety Science, 43, 739. (2005).

4. E. B. Shevkun, A. V. Leschinskiy, A. A. Piotrovich, Vestnik TOGU, 2, 93. (2014).

5. E.B. Shevkun, A.V. Leschinskiy, pat. 2317521 RF, patentoobladatel TOGU.

6. E.B. Shevkun, A.V. Leschinskiy, I. M. Urenev, G. P. Vagina, pat. 2310812 RF, patentoobladatel TOGU.

7. P.K. Singh, M.P. Roy, R.K. Paswan, Md. Sarim, S. Kumar, R. R. Jha, JRMGE, 8, 225. (2016).

8. A.V. Leschinskiy, E.B. Shevkun, N.K. Lukashevich, Vzryivnyie rabotyi pod ukryitiem v transportnom stroitelstve (Yurayt, Moskva, 2017).

9. N. Changping, J. Sjöbergb, D. Johanssona, N. Petropoulosa, IJRMMS, 100, 250. (2017).

10. W. Bangbiao, C. Rong, X. Kaiwen, IJRMMS, 80, 12. (2015).

a. Momeni, M. Karakus, G.R. Khanlari, M. Heidari, IJRMMS, 77, 89. (2015).

11. E. B. Shevkun, A. V. Leschinskiy, Yu. A. Lyisak, A. Yu. Plotnikov, GIAB, 4, 272 , (2017).

12. Yu. A Mityushkin., Yu. A. Lyisak, A. Yu. Plotnikov, A. V. Ruzhitskiy, E. B. Shevkun, A. V. Leschinskiy, GIAB, 4, 341. (2015).

13. A.D. Lovtsov, O.A. Kostiunina, Procedia Structural Integrity, 6C, 122. (2017).

14. T. A. Laursen, Computational Contact and Impact Mechanics (Springer-Verlag, Heidelberg, 2002).

15. I.E. Lyuminarskiy, Raschet uprugih sistem s odnostoronnimi svyazyami (MGIU, Moskva, 2006).

16. K. Rolf, W. Mirjam, 2012. Applied Numerical Mathematics, 10, 1393. (2012).

17. M. A. Crisfield, Non-linear finite elements analysis of solids and structures. Volume 1: Essentials (John Wiley and Sons, 1991).

18. M. A. Crisfield, Non-linear finite elements analysis of solids and structures. Volume 2: Advanced topics (John Wiley and Sons, 1997).

19. S. Oller, Nonlinear Dynamics of Structures (Springer, 2014). 